\title{
The mandatory humanity of the medical career
}

\section{La humanidad obligatoria de la carrera médica}

\author{
D’Ottavio-Cattani, Alberto Enrique ${ }^{1}$ \\ ${ }^{1}$ Facultad de Ciencias Médicas y Consejo de Investigaciones. Universidad Nacional de Rosario. Rosario, Argentina
}

\section{Dear Editor,}

This report extends a proposal raised several years ago (1) based on a personal experience timely carried out in the framework of a discipline: Histology and Embryology.

Since a medical career is one of the multiple accessing ways towards human beings, humanism is implicit in it. Thus, graduates could be metaphorically visualized as having a handful of keys provided by their career. Although the main one is aimed at goals like health promotion, prevention, diagnosis, treatment and rehabilitation, there remain others offering attractive possibilities for opening the trunk of humanities and arts.

While particularly depending on the graduate, this endeavor may be fostered by the medical curriculum, paying attention to questions like what, how and who, not only from the very beginning but also throughout the whole curriculum.

The contents to be faced may be related with Philosophy (Epistemology, Logic, Ethics and Axiology), Anthropology, Psychology, Sociology, History (World History and History of Science and Medicine) as well as Geography. Furthermore, it would be appropriate venturing into Literature, Painting, Sculpture, Architecture, Theater, Cinema and Music. The way ahead will require achieving a well-adjusted mixture of humanity-based knowledge and the traditional whole set of biological sciences supporting Medicine.

In this regard, traditional and innovated curricula offer a great deal of curricular (courses, seminars, workshops) and extracurricular opportunities, wherein TICs emerge as useful tools. Teachers may also take advantage of their own medical discipline by relating it with the abovementioned humanistic and/or artistic contents, whenever possible.

Instead of professionals mimicking teachers, such initiative demands real professional teachers able to work in an interdisciplinarity fashion using each cultural situation as a thematic trigger, incentive challenging, learning facilitator and/or mnemonic tool for memory reinforcement. In doing so, teachers and organizers will have to work conjointly.

Finally, the Letamendi's quotation: "The doctor who only knows Medicine, not even Medicine knows" sounds inspiring for achieving the mandatory endeavor of incorporating humanities and arts to the medical career.

\section{REFERENCE}

1. D’Ottavio AE. Ser Médico. Reflexiones sobre la formación y la práctica médicas. Editorial Homo Sapiens: Rosario; 2001 